\title{
Improvement the Resveratrol Content of Germinated Peanut Drink by Lactic Acid Fermentation
}

\author{
SongLok Uh ${ }^{1}$, IlJin Kim¹, KiBong Kim ${ }^{1}$, YongIl Seo ${ }^{1}$, KilNam Shin ${ }^{1}$, KiSun Li ${ }^{1}$, HaeSong Kim² \\ 1Pyongyang Jang Chol Gu University of Commerce, Pyongyang, Democratic People's Republic of Korea \\ 2Pyongyang Technology College of Food and Commodity, Pyongyang, Democratic People's Republic of Korea
}

\section{Article Info}

Volume 8 Issue 1

Page Number: 262-273

Publication Issue :

January-February-2021

\section{Article History}

Accepted : 20 Feb 2021

Published : 28 Feb 2021

\section{ABSTRACT}

Because peanut is a legume of nutrient abundance and contains a wide variety of chemical constituents such as proteins, carbohydrates, fibers, fats, niacin, folate, thiamine, resveratrol, flavonoids, magnesium, and phosphorus, a lot of research er focus the study on the peanut. Especially the peanut has high content of resve ratrol, so the health benefits including anti-aging, anticancer, anti-inflammatory and the prevention of cardiovascular disease, therefore the study that the peanu $t$ is used to process food and treat disease carried out widely. In this study, the co ndition to optimize the process programmes of fermentative germinated peanut drink by response surface experiment and to increase resveratrol contents by lact ic acid bacteria is determined. In order to improve the resvertrol contents of fer mentative germinated peanut drink, was prepared by using four-day germinated peanut as raw materials, adding Lactobacillus and xylitol before pasteurized, fer mentation and cold storge. By single factor analysis and response surface experi ments, the optimum conditions for fermentative germinated peanut drink were $t$ he amount of inoculum 3.26\%, the amount of xylitol $6.2 \%$, the fermentation tim e $15 \mathrm{~h}$ and the ratio of material to water $1: 5(\mathrm{~g} / \mathrm{mL})$. Product quality was evaluated through sensory evaluation. Investigate the change in resveratrol content of fer mentative germinated peanut drink by HPLC. Resveratrol contents were increas ed from $674.22 \pm 2.47 \mu \mathrm{g} / \mathrm{L}$ to $815.82 \pm 4.53 \mu \mathrm{g} / \mathrm{L}$ in germination peanut drink after fermentation.

Keywords : Germinated Peanut, Drink, Fermentation, Response Surface Experiments, Resveratrol

\section{INTRODUCTION}

Peanut (Arachis hypogaea) is an annual herbaceous plant which belongs to the Fabaceae family. Peanut is a legume of nutrient abundance and contains a wide variety of chemical constituents such as proteins,carbohydrates, fibers, fats, niacin, folate, thiamine, resveratrol, flavonoids, magnesium, and phosphorus[1]. Resveratrol (3, 4', 5trihydroxystilbene) is a major natural polyphenolic 
compound found in peanuts and peanut sprouts. Resveratrol belongs to the stilbene group and is synthesized by the enzyme resveratrol synthase, therefore the scientists studied to improve the resveratrol content of peanut drinksand germinated peanut drinks. The plant produces resveratrol as a defense mechanism against pathogen infection, UV radiation, and other mechanical stress damage. Recently, there has been a great deal of focus on resveratrol due to its health benefits including antiaging, anticancer, anti-inflammatory and the prevention of cardiovascular disease [2-4]. Fermentation is one of the oldest methods of food preservation. Its importance in today's life can be seen in the wide spectrum of fermented foods marketed both in developing and industrialized countries, not only for the benefit of preservation and safety, but also for the appreciated sensory qualities as well as enhanced health benefits of fermented products. Lactic acid bacteria (LAB) can affect the flavor of fermented foods in several ways, depending also on raw material composition. However, during fermentation, lactic acid bacteria undergo enzymatic hydrolysis and acidification [5], thus having a comprehensive impact on the structure of protein [69]. But the study to improve the resveratrol contents of germinated peanut drink with fermentation little carried out, and study on the fermentative germinated peanut drink were not got the optimalized value scientifically, and the interaction of all factors to process the fermentative germinated peanut drink was not determined. Therefore the purpose of this study is that the process programmes of fermentative germinated peanut drink is optimized by response surface experiment and detect the resveratrol contents of its.

\section{METHODS AND MATERIAL}

\subsection{Materials}

\section{(1) Materials}

The hull peanut (A. hypogaea L.) used in this study w ere purchased from a local supermarket in
Heilongjiang Province, China in 2020. 6

(2) Reagents

Xylitol (Sigma) were purchased from a local supermar ket in Heilongjiang Province, China in 2020. 6, LAB (Lactobacillus plantarum) were purchased from China Microbial Strain Preservation ManagementCenter in 2020. 6

Resveratrol (analytically pure) were purchased from XinSheng biological thechnology Co. Ltd in Heilongji ang Province, China in 2020.6

(3) Instruments

HR type constant temperature incubator, FLC-3 type aseptic condition working table

\section{SL-2 type sterilizer}

JYL-350B type cooking machine

SY11-KP2 type constant temperature water bath

YC-20BS3 type induction cooker

PT 2500E type homogenate machine

MIK-PH173 type acidity meter

HPLC (Agilent 1100)

(4) Period for experiment

From June 2020 to December 2020, an experiment wa s conducted at Northeast Agricultural University of C hina.

\subsection{Method}

(1) Peanut germination

The full and non-damaged grains were selected, rinse $\mathrm{d}$ with water, soaked in hot water at $80{ }^{\circ} \mathrm{C}$ for 5 minut es, quickly filtered, and 4 times water of the weight of peanuts was added. soaked at $20^{\circ} \mathrm{C}$ for $6 \mathrm{~h} \sim 8 \mathrm{~h}$. After imbibition, the peanuts were evenly seeded on the $\mathrm{pl}$ astic seedling tray, and germinated at $30{ }^{\circ} \mathrm{C}$ for $48 \mathrm{~h}$ in dark environmentof $80 \%$ humidity. Peel at germinate d peanut and store at low temperature for later use [7]. (2) Grinding of germinated peanut and Colloidal mill homogenization

To prepared germinated peanut drink, grind the ger minated peanut in $60^{\circ} \mathrm{C}$ hot water at a certain propor tion. The particle diameter of the peanut pulp ground by the beater is larger, and there are a large number o f coarse particles, which need to be polished by homo genate machine and filtering it through a 200 mesh si 
eve after slag removal. The particle size of the dispers ed phase is reduced to nanometer level, so as to impro ve the stability of the product [5].

(3) Seasoning

Xylitol and germinated peanut drink were mixed in a certain proportion, and then gently stirred evenly [5].

(4) Sterilization

After seasoning, the raw materials were put into steril izer and sterilized for $15 \mathrm{~min}$ at $121^{\circ} \mathrm{C}$ and $20 \mathrm{MPa}[8]$.

(5) Cooling

Cooling the sterilized raw material to $37^{\circ} \mathrm{C}[5]$.

(6) Vaccination to cultivate

Under aseptic conditions, the preserved Lactobacillus plantarum was activated by MRS solid medium plate a nd cultured at $37^{\circ} \mathrm{C}$ for $16 \mathrm{~h}$, and then inoculated in MRS liquid medium for expanded culture, cultured at $37{ }^{\circ} \mathrm{C}$ for $16 \mathrm{~h}$, and then inoculated in raw materials a ccording to a certain volume ratio[6].

(7) Fermentation

The inoculated raw materials were cultured at $37{ }^{\circ} \mathrm{C}$ [6].

(8) Post- ripening

After fermentation, the product was stored at $4{ }^{\circ} \mathrm{C}$ for $4 \mathrm{~h}$ for post-ripening[6].

(9) Single factor experiments

$\sim$ Selection of ratio of material to water in preparation of germinated peanut drink

Under the conditions of $6 \%$ xylitol, $3 \%$ LAB inoculat ion and $15 \mathrm{~h}$ fermentation time, the ratio of germinat ed peanut to water was selected as $1: 3,1: 4,1: 5,1: 6,1$ : 7 and 1:8 $(\mathrm{g} / \mathrm{mL})$, studied the effect of water supplem ental amount on germinated peanut drink respectivel y.

$\sim$ Selection of xylitol addition amount

The effects of xylitol on fermentation of germinated $p$ eanut drink were studied that xylitol supplemental le vels were selected as $3 \%, 4 \%, 5 \%, 6 \%, 7 \%$ and $8 \%$ un der the conditions that the ratio of germinated peanut to water was 1:5 $(\mathrm{g} / \mathrm{mL})$, the inoculation amount of $\mathrm{L}$ $A B$ was $3 \%$ and fermentation time of $15 \mathrm{~h}$ respectivel y.

Selection of inoculation amount of LAB
Under the conditions of germinated peanut to water $r$ atio of $1: 5(\mathrm{~g} / \mathrm{mL})$, xylitol content of $6 \%$, and fermen tation time of $15 \mathrm{~h}$, the inoculation amount of LAB w as selected as $1.5 \%, 2 \%, 2.5 \%, 3 \%, 3.5 \%$ and $4 \%$, resp ectively to study the effect of LAB inoculation amoun $\mathrm{t}$ on the fermentative germinated peanut drink.

Selection of fermentation time

The effects of fermentation time on germinated peanu $t$ drink were studied under the conditions of the ratio of germinated peanut to water was 1:5 (g/ mL), xylitol was $6 \%$, and the inoculation amount of LAB was $3 \%$. The fermentation time was selected as $12 \mathrm{~h}, 13 \mathrm{~h}, 14 \mathrm{~h}$, $15 \mathrm{~h}, 16 \mathrm{~h}$ and $17 \mathrm{~h}$ respectively.

$\sim$ Response surface experiment

The effect of the factors on the response were examin ed by a three-level, four-factor Box-Behnken design (BBD) [9]. The three independent variables included $\mathrm{i}$ noculation quantity of LAB (\%, X1), inoculation quan tity of xylitol (\%, X2), fermentation time (h, X3) and $r$ atio of material to water $(\mathrm{g} / \mathrm{mL}, \mathrm{X} 4)$. The coded and ac tual levels of the variables are presented in Table 2. A total of 29 experiments with five replicates at the cent er point were carried out. Regression analysis was per formed on the empirical data by fitting the quadratic model to them, as demonstrated below equation.

$\mathrm{Y}=\beta_{0}+\sum_{\mathrm{i}=1}^{3} \beta_{\mathrm{i}} \mathrm{X}_{\mathrm{i}}+\sum_{\mathrm{i}=1}^{3} \beta_{\mathrm{ii}} \mathrm{X}_{\mathrm{i}}^{2}+$

$\sum_{\mathrm{i}=1}^{2} \sum_{\mathrm{j}=\mathrm{i}+1}^{3} \beta_{\mathrm{ij}} \mathrm{X}_{\mathrm{i}} \mathrm{X}_{\mathrm{j}}$

where $\mathrm{Y}$ shows the dependent variable, $\beta_{0}, \beta_{0}$, $\beta_{\mathrm{i}}, \beta_{\mathrm{ii}}$ and $\beta_{\mathrm{ij}}$ represent the regression coeffificients for constant, linear, quadratic, and interactive effects, respectively; $\mathrm{Xi}$ and $\mathrm{Xj}$ denote the independent varia bles. The effects of the factors on the response were e xpressed as surface and contour plots to visualize the $r$ elationship between the response and the independen $t$ variables and to acquire the optimal conditions of th e process.

Sensory evaluation

The criterion of sensory evaluation on fermented ger minated peanut drink are shown in Table 1. 
Table 1. Sensory evaluation of fermentative germinated peanut pulp

\begin{tabular}{|c|c|c|c|c|}
\hline Sensory va & \multicolumn{4}{|c|}{ Characterization } \\
\hline Color(20 points) & $\operatorname{Milky}\left(17^{\sim} 20\right)$ & $\begin{array}{c}\text { Slight yellowish(13 } \\
\sim 16)\end{array}$ & Yellowish(9 12) & Yellow(5 8) \\
\hline Aroma(30 points) & $\begin{array}{c}\text { A rich aroma }\left(25^{\sim} 3\right. \\
0)\end{array}$ & $\begin{array}{c}\text { A rich aroma with s } \\
\text { light beany flavor(1 } \\
\left.\qquad 9^{\sim} 24\right)\end{array}$ & $\begin{array}{l}\text { Peanut aroma and s } \\
\text { erious beany flavor } \\
\qquad\left(13^{\sim} 18\right)\end{array}$ & $\begin{array}{c}\text { No peanut aroma w } \\
\text { ith severe beany fla } \\
\operatorname{vor}\left(7^{\sim} 12\right)\end{array}$ \\
\hline Taste(30 points) & $\begin{array}{l}\text { Sour, sweet and deli } \\
\text { cate peanut taste }(25 \\
\sim 30)\end{array}$ & $\begin{array}{l}\text { Less sour, sweet an } \\
\text { d delicate peanut ta } \\
\text { ste }\left(19^{\sim} 24\right)\end{array}$ & $\begin{array}{c}\text { Normal taste }\left(13^{\sim} 1\right. \\
8)\end{array}$ & $\begin{array}{l}\text { Rough and artificial } \\
\text { taste }\left(7^{\sim} 12\right)\end{array}$ \\
\hline $\begin{array}{l}\text { Appearance }(20 \text { poi } \\
n t s)\end{array}$ & $\begin{array}{l}\text { Homogeneous, stabl } \\
\text { e and } \\
\text { moderate consisten } \\
\text { cy }(17-20)\end{array}$ & $\begin{array}{l}\text { Relatively stable an } \\
\text { d normal } \\
\text { consistency (13-16) }\end{array}$ & $\begin{array}{l}\text { Unstable and insuffi } \\
\text { cient } \\
\text { consistency (9-12 }\end{array}$ & $\begin{array}{l}\text { Particularly unstabl } \\
\text { e and } \\
\text { inappropriate consi } \\
\text { stency (5-8) }\end{array}$ \\
\hline
\end{tabular}

※ull marks 100 points

(10) Cell count and acidity determination

Bacterial growth and acidification capacity were evalu ated the quality of fermentative germinated peanut $\mathrm{dr}$ ink [6]. For LAB count, $100 \mu \mathrm{L}$ of fermentative germi nated peanut drink were resuspended in $0.10 \%(\mathrm{w} / \mathrm{v})$ sterile peptone-water solution and serial dilutions wer e plated in MRS agar for all Lactobacillus plantarum $\mathrm{P}$ lates were incubated for $48-72 \mathrm{~h}$ at $30{ }^{\circ} \mathrm{C}$. Microbiolo gical quality of pasteurized fermentative germinated $\mathrm{p}$ eanut drink was evaluated in Mac Conkey agar ( $37 \circ \mathrm{C}$ and $45{ }^{\circ} \mathrm{C}, 48 \mathrm{~h}$ ) and E. coli and salmonella agar(20-25 $\mathrm{C}, 5-7$ days) to quantify coliforms, and E. coli and sa lmonella, respectively. Results were expressed as log c olony-forming units per milliliter (log CFU/mL). The acidity was measured by using a acidity meter. When the $15 \mathrm{~h}$-fermentation process was finished, drinks we re immediately placed at $4{ }^{\circ} \mathrm{C}$ for 21 days. Samples we re taken the last day of cold storage to determine bact erial count and acidity as previously described.

(11) Determination of resveratrol content Samples were analysed by HPLC as follows [10-11]: T he detecter is PDA (Shimadzu SPD-M 10A) detecter.
The column is Zorbax SB-C18 column $(250 \times 4.6 \mathrm{~mm}$, $5 \mu \mathrm{m})$, the eluents are acetontrile : water $=40: 60$, temp erature of column was set at $35^{\circ} \mathrm{C}$. The detection was set at a wavelength of $306 \mathrm{~nm}$. The flow was $0.8 \mathrm{~mL} /$ min. The volume injected was $10 \mu \mathrm{L}$.

\subsection{Statistical analysis}

All experiments were triplicated. Analysis of variance (ANOVA) of the results was performed using DesignExpert version 11. The statistical signifificance of the model terms was determined by calculating the F-val ue at confidence levels of $95 \%(\mathrm{P}<0.05)$ and $99 \%(\mathrm{P}<0$. $01)$. To determine the differences between the control sample and the optimized fermentative germinated $\mathrm{p}$ eanut drink,SPSS version 26 and the independent T-te st were used.

\section{RESULTS AND DISCUSSION}

\subsection{The results of single factor experiments}

(1) Determination of ratio of material to water in prep aration of germinated peanut drink 
The effect of ratio for germinated peanut and water on fermentative germinated peanut drink sensory quality is shown in Figure 1.

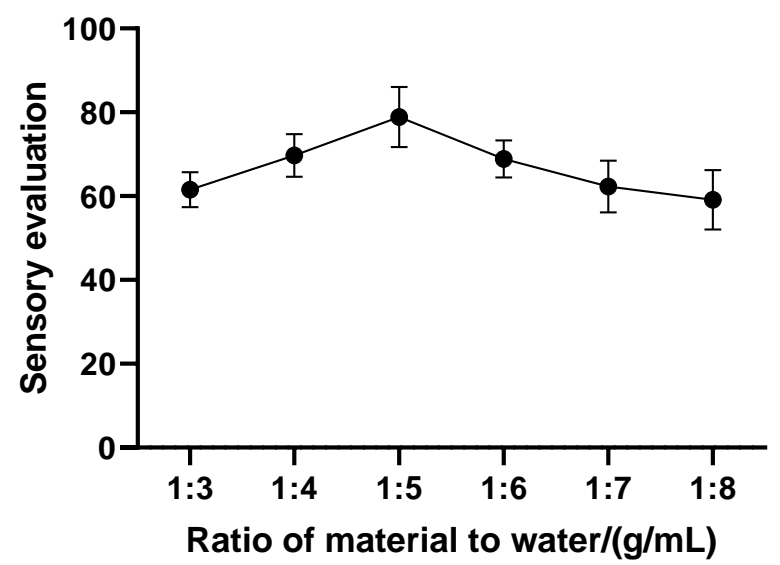

Figure 1. The effect of ratio for germinated peanut and water on fermentative germinated peanut drink sensory quality

As can be seen from Figure 1, the highest score was ac hieved when the ratio of germinated peanut to water was 1:5 (g/m L). Peanut aroma and germinal fragrance were more suitable and coordinated. When the ratio was greater than 1:5 (g/ mL), the peanut aroma was to o strong, and when the ratio was lower than $1: 5(\mathrm{~g} / \mathrm{m}$ $\mathrm{L})$, the peanut aroma gradually became weak. Therefo re, the ratio of germinated peanut to water selected 1 : 5 (g/ mL) to carry out the following studies.

(2) The effect of the amount of xylitol on fermentativ e germinated peanut drink sensory quality

The effect of the amount of xylitol on fermentative ge rminated peanut drink sensory quality is shown in Fig ure 2.

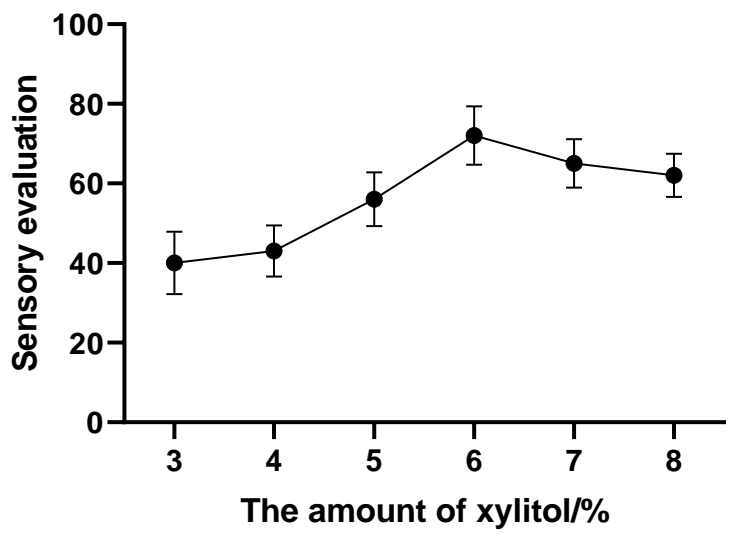

Figure 2. The effect of the amount of xylitol on fermentative germinated peanut drink sensory quality

As can be seen from Figure 2, if the addition amount of xylitol is too low, the sour taste will be too heavy; i $\mathrm{f}$ the addition amount is too high, the aroma of germi nated peanut drink will be covered up and the taste $\mathrm{w}$ ill be too sweet and greasy.

The content of xylitol was about $6 \%$, the sensory qual ity of fermentative germinated peanut drink was the best, and the sweet and sour were moderate. Finally $t$ he additive amount of xylitol was determined to be 6 $\%$.

(3) The effect of the amount of inoculum on fermenta tive germinated peanut drink sensory quality.

The effect of the amount of inoculum on fermentative germinated peanut drink sensory quality is shown in Figure 3.

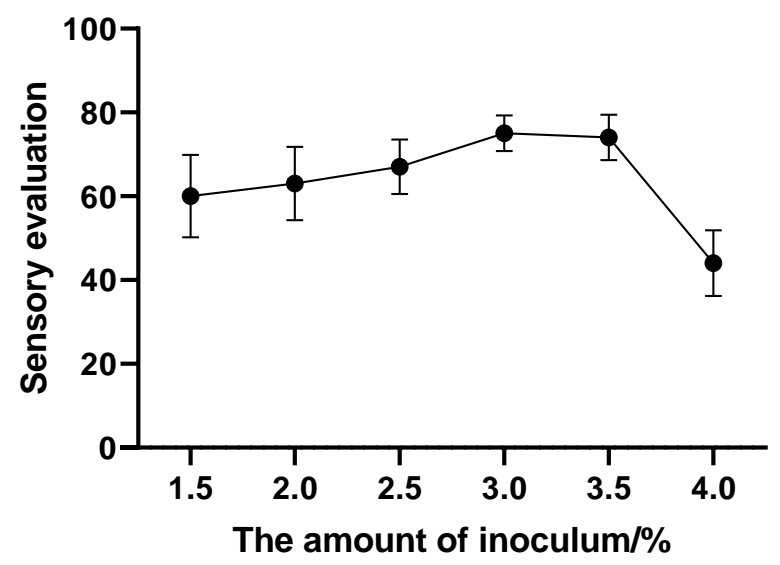

Figure 3. The effect of the amount of inoculum on fermentative germinated peanut drink sensory quality 
As can be seen from Figure 3, when the amount of in oculum was less than $3 \%$, the clear liquid of fermenta tive germinated peanut drink was precipitated, resulti $\mathrm{ng}$ in less acid production and less sour taste. When th e amount of inoculum was about 3\% 3.5\%, fermenta tive germinated peanut drink was suitable for sweet a nd sour, and the taste was delicate. Finally the amoun $\mathrm{t}$ of inoculum was determined to be $3 \%$.

(4) The effect of fermentation time on fermentative $g$ erminated peanut drink sensory quality

The effect of fermentation time on fermentative germ inated peanut drink sensory quality is shown in Figur e 4 .

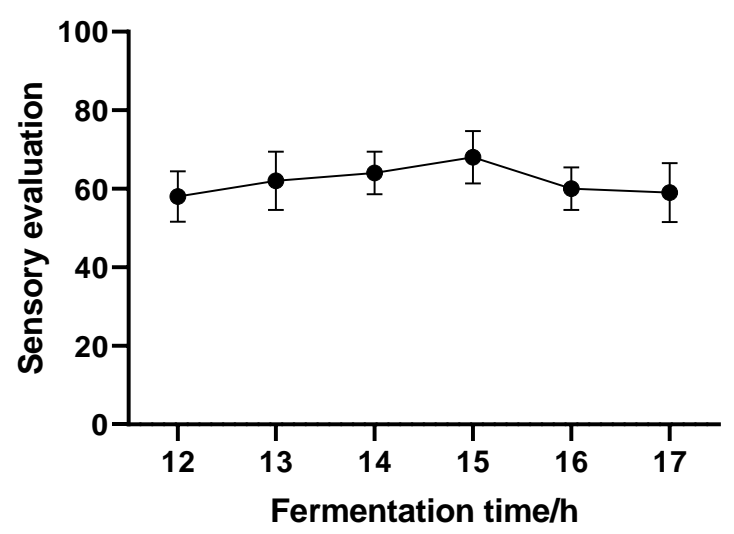

As can be seen from Figure 4, if the fermentation time is too short, the acidity is insufficient. Fermentation $t$ ime is too long, sour taste is too heavy, sour and sweet taste imbalance.

The fermentation time was about $15 \mathrm{~h}$, and the germi nated peanut drink had the best sensory quality, suita ble for sweet and sour, delicate taste and uniform text ure. The fermentation time was finally determined to be $15 \mathrm{~h}$.

\subsection{The results and analysis of Response surface}

\section{experiment}

The range of the independent variables and their corr esponding levels is shown in Table 2.

Figure 4. The effect of fermentation time on ferment ative germinated peanut drink sensory quality

Table 2. The range of the independent variables and their corresponding levels

\begin{tabular}{ccccc}
\hline Code & & \multicolumn{3}{c}{ Coded levels } \\
\hline $\begin{array}{c}\text { Independent } \\
\text { variables } \\
\begin{array}{c}\text { The amount of } \\
\text { inoculum/\% }\end{array}\end{array}$ & Symbol & -1 & 0 & +1 \\
$\begin{array}{c}\text { The amount of } \\
\text { xylitol/\% }\end{array}$ & $\mathrm{X}_{1}$ & 2 & 3 & 4 \\
$\begin{array}{c}\text { Fermentation time/h } \\
\text { Ratio of material to } \mathrm{w} \\
\text { ater/(g/mL) }\end{array}$ & $\mathrm{X}_{3}$ & 5 & 6 & 7 \\
\hline
\end{tabular}

The results of Box-Behnken experiments design using the Design-Expert 11 software are shown in Table 3. 
Table 3. Response Surface Design and Sensory Scores

\begin{tabular}{|c|c|c|c|c|c|}
\hline \multirow[b]{2}{*}{ Run } & \multicolumn{4}{|c|}{ Factors } & \multirow[b]{2}{*}{ Sensory evaluation } \\
\hline & $\mathrm{X}_{1}:$ Inoculum/\% & $\mathrm{X}_{2}:$ Xylitol/\% & $\mathrm{X}_{3}:$ Time/h & $\mathrm{X}_{4}:$ Ratio/(g/mL) & \\
\hline 1 & 3 & 5 & 15 & 6 & 71.6 \\
\hline 2 & 4 & 6 & 15 & 4 & 84.5 \\
\hline 3 & 4 & 5 & 15 & 5 & 75.8 \\
\hline 4 & 2 & 6 & 15 & 6 & 70.6 \\
\hline 5 & 3 & 6 & 15 & 5 & 93.2 \\
\hline 6 & 2 & 6 & 14 & 5 & 62.4 \\
\hline 7 & 3 & 6 & 15 & 5 & 92.5 \\
\hline 8 & 4 & 7 & 15 & 5 & 81.4 \\
\hline 9 & 3 & 5 & 16 & 5 & 80.1 \\
\hline 10 & 3 & 7 & 16 & 5 & 82.6 \\
\hline 11 & 4 & 6 & 16 & 5 & 82.3 \\
\hline 12 & 4 & 6 & 15 & 6 & 78.7 \\
\hline 13 & 3 & 5 & 14 & 5 & 68.1 \\
\hline 14 & 3 & 6 & 14 & 6 & 75.8 \\
\hline 15 & 3 & 6 & 15 & 5 & 90.1 \\
\hline 16 & 3 & 7 & 14 & 5 & 72.1 \\
\hline 17 & 2 & 5 & 15 & 5 & 72.5 \\
\hline 18 & 4 & 6 & 14 & 5 & 79.5 \\
\hline 19 & 3 & 6 & 16 & 6 & 77.1 \\
\hline 20 & 3 & 5 & 15 & 4 & 74.4 \\
\hline 21 & 3 & 7 & 15 & 6 & 89.8 \\
\hline 22 & 3 & 6 & 16 & 4 & 82.8 \\
\hline 23 & 2 & 6 & 16 & 5 & 73.5 \\
\hline 24 & 3 & 6 & 15 & 5 & 89.8 \\
\hline 25 & 2 & 6 & 15 & 4 & 69.1 \\
\hline 26 & 3 & 7 & 15 & 4 & 75 \\
\hline 27 & 2 & 7 & 15 & 5 & 74.8 \\
\hline 28 & 3 & 6 & 14 & 4 & 64.2 \\
\hline 29 & 3 & 6 & 15 & 5 & 92.9 \\
\hline
\end{tabular}

The Design-Expert version 11 software was used to conduct square error analysis on the data in Table 3, and th e results were shown in Table 4. Taking the amount of inoculum $\left(\mathrm{X}_{1}\right)$, the amount of xylitol $\left(\mathrm{X}_{2}\right)$, the fermentati on time $\left(\mathrm{X}_{3}\right)$ and the ratio of material to water $(\mathrm{X} 4)$ as the influencing factors, and the sensory score $(\mathrm{Y})$ as the $\mathrm{r}$ esponse value, the multiple quadratic regression equation for the fermentation process optimization of ferment ative germinated peanut drink was as below equation: 
The correction coefficient of the model $\mathrm{R}^{2}=0.9435$ and $\mathrm{RAdj}^{2}=0.8871$ indicate that the model has good fitting deg ree and small experimental error, so the model is suitable.

Table 4. Analysis of variance of Box-Behnken design (BBD)

\begin{tabular}{cccccccc}
\hline Source & Sum of Squares & $\mathrm{df}$ & Mean Square & F-value & p-value & significant \\
\hline Model & 1923.49 & 14 & 137.39 & 16.71 & $<0.0001$ & $* *$ \\
$\mathrm{X}_{1}$-Inoculum & 293.04 & 1 & 293.04 & 35.64 & $<0.0001$ & $* *$ \\
$\mathrm{X}_{2}$-Xylitol & 91.85 & 1 & 91.85 & 11.17 & 0.0048 & $* *$ \\
$\mathrm{X}_{3}$-Time & 264.14 & 1 & 264.14 & 32.12 & $<0.0001$ & $* *$ \\
$\mathrm{X}_{4}$-Ratio & 15.41 & 1 & 15.41 & 1.87 & 0.1925 & \\
$\mathrm{X}_{1} \mathrm{X}_{2}$ & 2.72 & 1 & 2.72 & 0.3311 & 0.5742 & \\
$\mathrm{X}_{1} \mathrm{X}_{3}$ & 17.22 & 1 & 17.22 & 2.09 & 0.1699 & \\
$\mathrm{X}_{1} \mathrm{X}_{4}$ & 13.32 & 1 & 13.32 & 1.62 & 0.2238 & \\
$\mathrm{X}_{2} \mathrm{X}_{3}$ & 0.5625 & 1 & 0.5625 & 0.0684 & 0.7975 & \\
$\mathrm{X}_{2} \mathrm{X}_{4}$ & 77.44 & 1 & 77.44 & 9.42 & 0.0083 & $* *$ \\
$\mathrm{X}_{3} \mathrm{X}_{4}$ & 74.82 & 1 & 74.82 & 9.10 & 0.0092 & $* *$ \\
$\mathrm{X}_{1}{ }^{2}$ & 467.73 & 1 & 467.73 & 56.88 & $<0.0001$ & $* *$ \\
$\mathrm{X}_{2}{ }^{2}$ & 304.73 & 1 & 304.73 & 37.06 & $<0.0001$ & $* *$ \\
$\mathrm{X}_{3}{ }^{2}$ & 533.22 & 1 & 533.22 & 64.84 & $<0.0001$ & $* *$ \\
$\mathrm{X}_{4}{ }^{2}$ & 358.01 & 1 & 358.01 & 43.54 & $<0.0001$ & $* *$ \\
Residual & 115.12 & 14 & 8.22 & & & \\
Lack of Fit & 104.62 & 10 & 10.46 & 3.99 & 0.0974 & not significant \\
Pure Error & 10.50 & 4 & 2.63 & & & \\
Cor Total & 2038.61 & 28 & & & & \\
\hline
\end{tabular}

$\aleph^{* *}$ means that it has a very significant effect on the results $(\mathrm{P}<0.01)$

As can be seen Table 4, the model F-value of 16.71 with a low probability P-value of less than 0.0001 indicted $\mathrm{h}$ igh signifificance of the model. The lack of fit for an F-value of 3.99 meant that this term was not signifificantly relative to the pure error, the nonsignifificant value of lack fit $(>0.05)$ showed that the quadratic model was val id for this study. From the results in Table 4, the amount of inoculum, the amount of xylitol and fermentation $t$ ime had high significant effects on the sensory score of fermentative germinated peanut $\operatorname{drink}(\mathrm{p}<0.01)$, then the ratio of material to water had no significant effects $(\mathrm{P}>0.05)$.
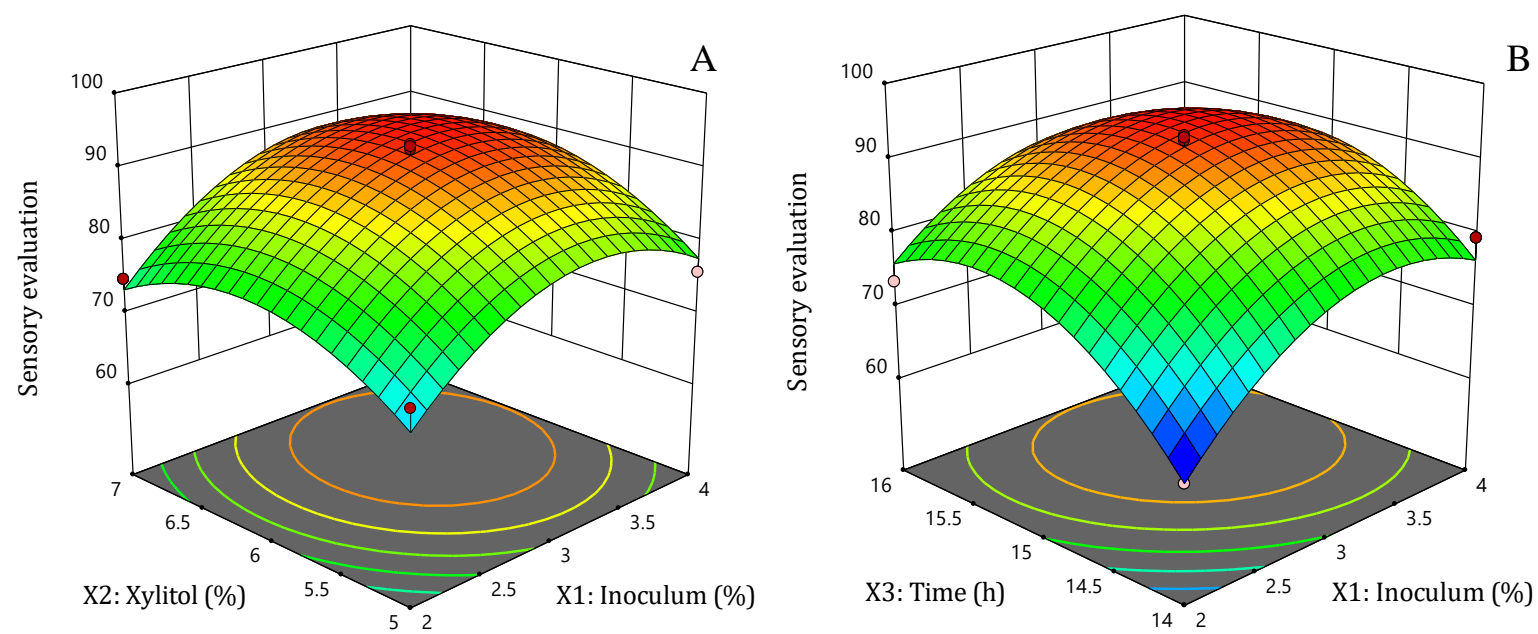

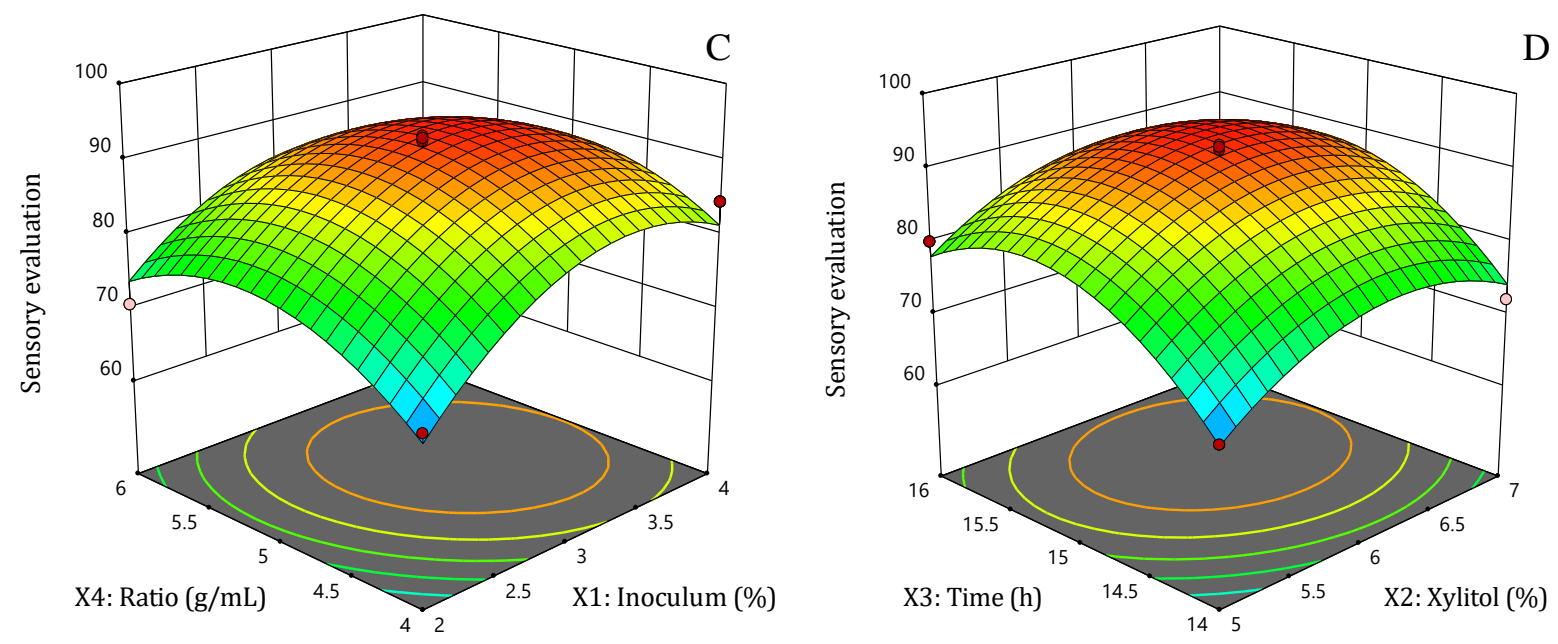

$\mathrm{D}$
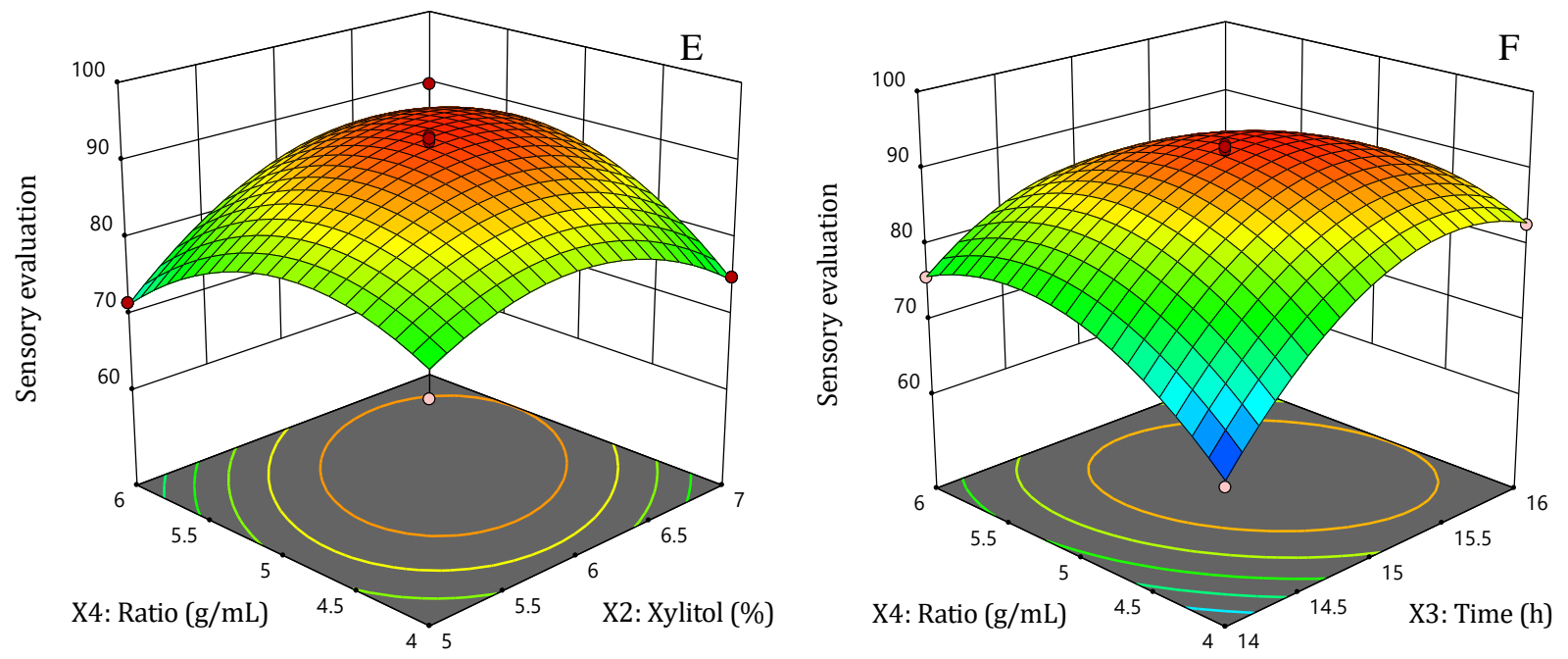

Figure 5. Response surface plots and contour lines of effects of interaction between each factor on sensory scores of fermentative germinated peanut drink

It can be seen from Figure 5 that the curve of the amount of inoculum and fermentation time is the steepest, fol lowed by the amount of xylitol, and the last is the ratio of material to water. As be shown Figure 5E and Figure $5 \mathrm{~F}$, the interaction between the amount of xylitol and the ratio of material to water, as well as fermentation tim e and the ratio of material to water, which is consistent with the results of variance analysis in Table 4 . Thourg $\mathrm{h}$ the optimizing of fermentative germinated peanut drink processing by response surface experiment, determin ed that the optimal condition of its process is the amount of inoculum 3.26\%, the amount of xylitol $6.2 \%$, the fe rmentation time $15 \mathrm{~h}$ and the ratio of material to water $1: 5(\mathrm{~g} / \mathrm{mL})$. Three parallel validation tests were carried o ut under this optimized condition, and the sensory score of fermentative germinated peanut drink was 93.10 po ints, which was not much different from the theoretical value of 93.20 points, which proved that the prediction results of this model were reasonable and reliable.

\subsection{Testing of nutritional factors and microbiological counts in fermentative germinated peanut drink}

The nutritional factors and microbiological counts in fermentative germinated peanut drink shown in Table 5. 
Table 5. Results nutritional factors and microbiological counts in fermentative germinated peanut drink

\begin{tabular}{|c|c|c|c|c|}
\hline \multirow[b]{2}{*}{ Indexs } & \multicolumn{3}{|c|}{ Experimental number } & \multirow[b]{2}{*}{ Mean proportion } \\
\hline & 1 & 2 & 3 & \\
\hline Acidity/To & 74.30 & 76.40 & 76.30 & 75.67 \\
\hline $\begin{array}{c}\text { Lactobacillus } \\
\text { plantarum/(log CFU/ } \\
\mathrm{mL})\end{array}$ & 3.88 & 3.86 & 3.88 & 3.87 \\
\hline $\begin{array}{l}\text { Total number of bact } \\
\text { eria/ }(\mathrm{MPN} / \mathrm{m} \mathrm{L})\end{array}$ & 53 & 49 & 52 & 51.33 \\
\hline E. coli/(log CFU/mL) & 0 & 0 & 0 & 0 \\
\hline $\begin{array}{c}\text { Salmonella/(log CFU/ } \\
\mathrm{mL})\end{array}$ & ND & ND & ND & ND \\
\hline
\end{tabular}

※D: not detect

It can be seen from Table 5 that pathogenic bacteria cannot be detected according to international standards[6], Escherichia coli should not exceed $3 \mathrm{MPN} / \mathrm{mL}$, and the total number of colonies should not exceed $100 \mathrm{CFU} / \mathrm{m}$ $\mathrm{L}$, all the monitored indexes in the fermentative germinated peanut drink meet the requirements of internation al standards.

\subsection{The resveratrol content}

The resvertrol content shown in Table 6.

Table 6. The content measurement results of resveratrol

\begin{tabular}{|c|c|}
\hline Samples & Resvertrol content $/(\mu \mathrm{g} / \mathrm{L})$ \\
\hline $\begin{array}{l}\text { Fermentative germinated peanut } \mathrm{d} \\
\text { rink }\end{array}$ & $815.82 \pm 4.53$ \\
\hline Germinated peanut drink & $674.22 \pm 2.47^{*}$ \\
\hline Fermentative peanut drink & $158.38 \pm 4.21^{* *}$ \\
\hline Peanut drink & $81.06 \pm 2.13^{* *}$ \\
\hline
\end{tabular}

The table 6 shows that parallel test showed that 10 ti mes of resveratrol content in the fermented germinat ed peanut drink was $815.82 \mu \mathrm{g} / \mathrm{L}$, and peanut resverat rol content is only $1 / 10$ of the resveratrol content in $t$ he fermentative germinated peanut drink, increased $t$ he resveratrol content of fermented peanut drink, but compared with fermentative germinated peanut drin $k$, resveratrol content before and after fermentation $h$ as declined significantly $(\mathrm{P}<0.05)$, the content of resve ratrol in germinated peanut drink was significantly lo wer than that in fermentative germinated peanut drin $\mathrm{k}(<0.05)$, but significantly higher than that of peanut drink and fermented peanut drink.

\section{DISCUSSION}

Peanut sprouts belong to sprouts like soybean sprouts and mung bean sprouts. Peanut sprouts are rich in a $\mathrm{v}$ 
ariety of nutrients, especially high content of resverat rol, so the health benefits including anti-aging, antica ncer, anti-inflammatory and the prevention of cardio vascular disease of the new sprouts varieties, quite po pular with consumers. And because the lactic acid bac terium itself is isolated from fermented pickle, it has e xcellent performance for plant fermentation, and ani mal milk contains cholesterol and lactose, and some $\mathrm{p}$ eople, such as hyperlipidemia patients, may not be sui table for excessive cholesterol intake, a large of people needs the fermentative vegetable drinks. The peanut during germinative period decresaed fatty contents su ch as cholesterol, resveratrol contents increased, and during fermentation, lactic acid bacteria undergo enz ymatic hydrolysis and acidification, thus having a co mprehensive impact on the structure of proteins. The refore in this study, the process programmes of ferme ntative germinated peanut drink is optimized by resp onse surface experiment and detected the level of im proving functional property of its. As be shown Table 4 and Figure 5, the main factors affecting the quality of the beverage were tested by response surface experi ment, and the optimum proportion was determined. According above table and figure, determined that th e ratio of material to water are not significant factors $i$ $\mathrm{n}$ the process of fermentative germinated peanut drin $\mathrm{k}$, that the amount of inoculum, fermentation time an $d$ the amount of inoculum is high significant. Thourg $h$ response surface experiment, verified that the optim um conditions for fermentative germinated peanut dri nk were the amount of inoculum 3.26\%, the amount of xylitol $6.2 \%$, the fermentation time $15 \mathrm{~h}$ and the rat io of material to water $1: 5(\mathrm{~g} / \mathrm{mL})$. A fermentative ger minated peanut drink was prepared, which was milky in color, glossy, delicate in taste, suitable in sour and sweet, and had strong peanut flavor and fresh fragran ce of the sprout. Under this optimized condition, the s ensory score of fermentative germinated peanut drink was 93.10 points. After fermentation, animal milk is not added, which enlarges the applicable population $\mathrm{o}$ $\mathrm{f}$ this drink. As be shown Table 6, the resveratrol cont ents of germination peanut drink were increased from
$674.22 \pm 2.47 \mu \mathrm{g} / \mathrm{L}$ to $815.82 \pm 4.53 \mu \mathrm{g} / \mathrm{L}$ after fermentat ion. Therefore, verified that germinated peanut drink uses lactic acid bacteria is straighten the functional pr operty of its, And in this study, the use of high temper ature instantaneous sterilization fully ensures the min imum loss of nutrients. As be shown Table 5, the path ogenic bacteria cannot be detected, Escherichia coli s hould not exceed $3 \mathrm{MPN} / \mathrm{mL}$, and the total number o $\mathrm{f}$ colonies should not exceed $100 \mathrm{CFU} / \mathrm{mL}$, all the mon itored indexes in the fermentative germinated peanut drink meet the requirements of international standard s.

\section{CONCLUSION}

The optimum technological parameters were determined through the research on the production technology of fermentative germinated peanut drink by response surface experiment. The optimum conditions for fermentative germinated peanut drink is that the amount of inoculum $3.26 \%$, the amount of xylitol $6.2 \%$, the fermentation time $15 \mathrm{~h}$ and the ratio of material to water $1: 5(\mathrm{~g} / \mathrm{mL})$. Under these conditions, the sensory score of fermentative germinated peanut drink was the highest. After the acidity and the microbiological tests, the indicators reached the international standards. The drink was found to be rich in resveratrol through HPLC experiment, and the contents increased at about 1.2 times than germinated peanut drink.

\section{REFERENCES}

[1]. Qiong-Qiong Yang, Comparison of the Phenolic Profiles of Soaked and Germinated Peanut Cultivars via UPLC-QTOFMS,JAntioxidants, $2019.8: 1-12$

[2]. Qingping Xiong, Preliminary separation and purification of resveratrol from extract of peanut (Arachis hypogaea) sprouts by macroporous adsorption resins, J Food Chemistry, 2013.9:1-7 
[3]. Jain-Song Ju, Commercialized machine for soaking and slicing peanuts to induce resveratrol production,JJournal of Food Process Engineering,2017;e12611:1-11

[4]. Scott A. Snyder, Total Synthesis of ResveratrolBased Natural Products:A Chemoselective Solution,JAngewandte chemie, 2007.119 :83348339

[5]. Claudia Cristina Auler do Amaral Santos,Coculture fermentation of peanut-soy milk for the development of a novel functional beverage,JInternational Journal of Food Microbiology,2014.186:32-41

[6]. Alberto Niccolai, Lactic Acid Fermentation of Arthrospira platensis (Spirulina) in a Vegetal Soybean Drink for Developing New Functional Lactose-Free Beverages , JFrontiers in Microbiology,2010.10:1-18

[7]. Miao $\mathrm{Yu}$, Optimisation for resveratrol accumulation during peanut germination with phenylalanine feeding \& ultrasound-treatment using response surface methodology,JInternational Journal of Food Science and Technology,2016. 51:938-945

[8]. Liangjie Tian, Effects of short-term fermentation with lactic acid bacteria on the characterization, rheological and emulsifying properties of egg yolk,JFood Chemistry, 2020.9:1-38

[9]. Guowen Zhang, Optimization of microwaveassisted enzymatic extraction of polyphenols from waste peanut shells and evaluation of its antioxidant and antibacterial activities in vitro,JFood and Bioproducts Processing, 2013,91:158-168

[10]. Kadriye Busra Karatay,Isolation of resveratrol from peanut sprouts, radioiodination and investigation of its bioactivity on neuroblastoma cell lines,JJournal of Radioanalytical and Nuclear Chemistry,2020.3:1-10
[11]. Kritamorn Jitrangsri, Supercritical fluid extraction (SFE) optimization of trans resveratrol from peanut kernels (Arachis hypogaea) by experimental design,JJournal of Food science and Technology, 2020.9:1-9

\section{Cite this article as :}

SongLok Uh, Iljin Kim, KiBong Kim, YongIl Seo, KilNam Shin, KiSun Li, HaeSong Kim, "Improvement the Resveratrol Content of Germinated Peanut Drink by Lactic Acid Fermentation ", International Journal of Scientific Research in Science, Engineering and Technology (IJSRSET), Online ISSN : 2394-4099, Print ISSN : 2395-1990, Volume 8 Issue 1, pp. 262-273, January-February 2021. Available at doi : https://doi.org/10.32628/IJSRSET218150 Journal URL : https://ijsrset.com/IJSRSET218150 